\title{
A Multicenter, Long-Term Study on Arrhythmias in Children with Ebstein Anomaly
}

\author{
Tammo Delhaas • Gideon J. du Marchie Sarvaas • \\ Marry E. Rijlaarsdam · Jan L. Strengers · Rhona M. Eveleigh • \\ Sumayah E. Poulino $\cdot$ Chris L. de Korte $\cdot$ Livia Kapusta
}

Received: 16 July 2009/ Accepted: 30 October 2009/Published online: 24 November 2009

(C) The Author(s) 2009. This article is published with open access at Springerlink.com

\begin{abstract}
To assess the prevalence, history, and treatment of arrhythmias, in particular preexcitation and Wolff-Parkinson-White (WPW) syndrome, in patients with Ebstein anomaly (EA) during childhood and adolescence, we performed a multicenter retrospective study of all consecutive live-born patients with EA, diagnosed, and followed by pediatric cardiologists between 1980 and 2005 in The Netherlands. During a follow-up after EA diagnosis of 13 years 3 months (range: 6 days to 28 years 2 months), $16(17 \%)$ of the 93 pediatric EA patients exhibited rhythm disturbances. Nine patients showed arrhythmic events starting as of the neonatal period. Supraventricular tachycardia was noted in 11 patients. One patient died in the neonatal period due to intractable supraventricular tachycardia resulting in heart failure and one patient died at
\end{abstract}

\section{T. Delhaas $(\bowtie)$}

Department of Pediatrics, Maastricht University Medical Center,

Maastricht, The Netherlands

e-mail: t.delhaas@fys.unimaas.nl

G. J. du Marchie Sarvaas

Department of Pediatric Cardiology, University Medical

Center Groningen, Groningen, The Netherlands

M. E. Rijlaarsdam

Center for Congenital Anomalies of the Heart Amsterdam/

Leiden, Leiden University Medical Center, Leiden,

The Netherlands

\section{J. L. Strengers}

Department of Pediatric Cardiology, Network for Congenital

Heart Disease Utrecht-Rotterdam, Wilhelmina Children's

Hospital, University Medical Center Utrecht, Utrecht,

The Netherlands

R. M. Eveleigh - S. E. Poulino - C. L. de Korte - L. Kapusta Children's Heart Center, Radboud University,

Nijmegen Medical Center, Radboud, The Netherlands
5 weeks of age most probably due to an arrhythmic event. The 14 surviving patients all show preexcitation, albeit 4 of them intermittently, and all have a right-sided accessory pathway location. Nine patients underwent catheter ablation of an accessory pathway. Only four patients are currently on antiarrhythmic drugs. The $17 \%$ prevalence of rhythm disturbances in pediatric EA patients, most commonly supraventricular arrhythmias, is significantly lower than in adult EA patients. Life-threatening rhythm disturbances are not frequent early in life. Symptomatic patients are well treated with radiofrequency catheter ablation.

Keywords Ebstein anomaly - Cardiac arrhythmias . Preexcitation

\section{Introduction}

Ebstein anomaly (EA) accounts for $<1 \%$ of all congenital heart diseases and is characterized by apical displacement of the posterior and septal leaflets of the tricuspid valve $[2,21]$. The downward displacement of the septal tricuspid valve leaflet is associated with discontinuity of the central fibrous body and septal atrioventricular ring and, hence, with direct muscular connections. Thus, a potential substrate for accessory atrioventricular connections and ventricular preexcitation is created [10]. This is reflected in the fact that preexcitation and Wolff-Parkinson-White (WPW) syndrome are more frequently associated with EA than with any other congenital heart defect [16], with a reported prevalence varying between 0 and $44 \%[2,3,6,7,9,11,13,14,17$, $18,24,25,27]$. However, agreement on the prevalence in the young EA population is lacking. The objective of this retrospective study was to assess the prevalence, history, and treatment of arrhythmias, in particular preexcitation and 
WPW syndrome, in patients with EA during childhood and adolescence.

\section{Methods}

All six Dutch pediatric heart centers granted access to the medical records of all consecutive live-born patients with EA, diagnosed, and followed by a pediatric cardiologist at one of these centers between January 1, 1980 (when echocardiography was routinely used) and March 30, 2005. An apical or downward displacement of the tricuspid valve from the atrioventricular valve $\operatorname{ring} \geq 0.8 \mathrm{~cm} / \mathrm{m}^{2}$ body surface area was set as the criterion for EA. Excluded were only patients with congenitally corrected transposition of the great arteries. Medical records were examined for history of subjective and/or objective signs of arrhythmias. Resting 12-lead ECGs as well as 24-h ECGs were analyzed (by Tammo Delhaas) for preexcitation or arrhythmic events. In case of preexcitation, the most likely site of the accessory pathway was located by means of the QRS polarity in all ECG leads using both the pediatric algorithm devised by Boersma et al. [4] as well as the algorithm devised by d'Avila et al. [8] for adults. When possible, the pathways according to these algorithms were compared with the pathway as detected during invasive electrophysiology study and catheter ablation.

\section{Results}

For details on the results of this full cohort study on the perinatal and neonatal course along with the follow-up period during childhood and adolescence, we refer to the work by Kapusta et al. [15]. In short, 93 pediatric EA patients diagnosed, followed, and treated in one of the 6 Dutch pediatric heart centers were included in that study: 41 males and 52 females. Sixty $(64.5 \%)$ patients were diagnosed with EA during the first 2 months of life, 6 (6.5\%) between 3 and 12 months of age, and 27 (29\%) beyond the first year of age.

Of the above-mentioned 93 EA patients, 16 (17\%) exhibited rhythm disturbances. Patient characteristics of the latter 16 EA patients are described in Table 1. The median age at diagnosis of this subgroup of EA patients was 0 days (range: 0 days to 13 years 6 months). The median age at first ECG abnormality was 3 months (range: 0 days to 17 years 7 months). Follow-up after EA diagnosis was 13 years 3 months (range: 6 days to 28 years 2 months). Follow-up after first ECG abnormality was 9 years 7 months (range: 6 days to 18 years 4 months).

Five EA patients presented with a supraventricular tachycardia (SVT). One patient had an intractable SVT and he died at 6 days of age. The other four who could be conversed to sinus rhythm subsequently showed preexcitation. Three EA patients with preexcitation were detected on routine ECG at initial diagnosis of EA, whereas the other seven presented later in life with rhythm disturbances and were then found to have preexcitation. One patient was reported to have succumbed at 1 month 6 days of age most probably due to an arrhythmic event.

All of the 14 surviving patients show preexcitation, albeit 4 of them intermittently. Only one patient remained symptom-free. The most likely site of the accessory pathway was at the right side in all patients ( 8 right lateral, 5 right posteroseptal, 1 anteroseptal) when we located the pathway according to the QRS polarity-based pediatric algorithm as devised by Boersma et al. [4]. Using the adult d'Avila algorithm [8], the location of the pathway should be located in three patients on the left side. The location of the accessory pathway as detected during catheter ablation was always right-sided, even in one of the patients who would have had a left-sided pathway according to the adult algorithm. Only one patient had two pathways at different locations. In eight patients, periods with SVT led to catheter ablation of accessory pathways. In five patients, one accessory pathway was successfully ablated. Of the three patients who needed two ablation sessions, the one with the right-sided Mahaim fibers still has infrequent antidromic SVT. In one patient, catheter ablation was performed because the accessory pathway always conducted and the amount of preexcitated muscular tissue was so excessive that he had dyssynchrony-induced cardiomyopathy. In this patient, the anterograde conduction possibility of the AV node was tested before ablation. The first ablation was unsuccessful. Nine months later, this patient underwent a second, now successful ablation but showed a right bundle branch block since then. Because of mild heart failure, he is still on enalapril and metoprolol.

Of the nine patients who underwent catheter ablation of an accessory pathway, five were completely symptom-free after the procedure. One patient showed nonsustained right bundle branch block (RBBB) postablation, whereas another one showed persistent RBBB. The one patient with the Mahaim fibers still has infrequent antidromic SVT. The remaining one patient with persistent symptoms postablation had a short period of ectopic atrial tachycardia postablation and a persistently increased PR interval.

Only four patients are currently on antiarrhythmic drugs: one because of infrequent SVT while never ablated, one because of infrequent antidromic SVT despite two ablation sessions for Mahaim fibers, one because of ventricular fibrillation in the neonatal period, and the last one because of mild heart failure.

Three patients (19\%) had been operated on for their EA, without any surgical antiarrhythmic procedure. Two 


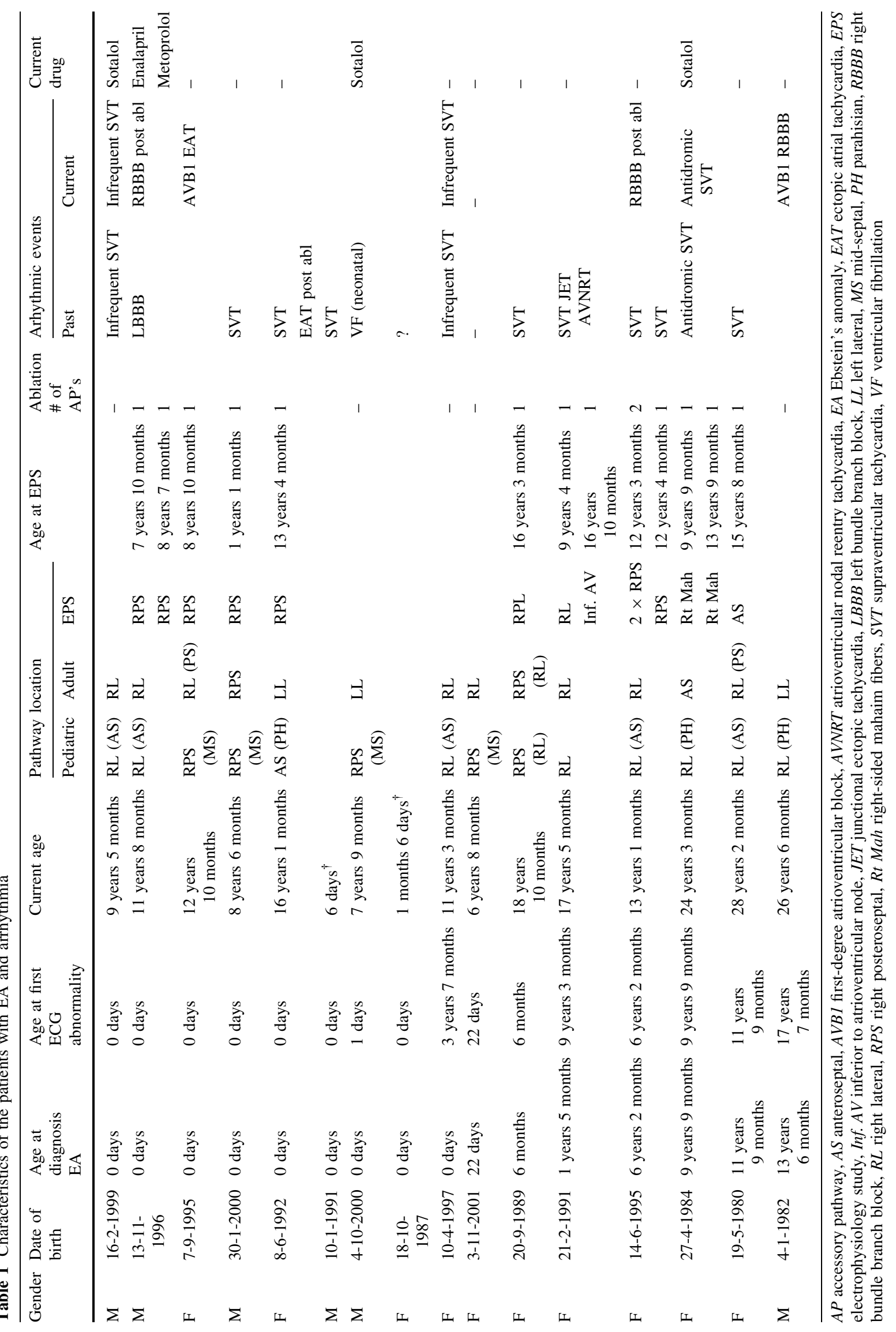


underwent a tricuspid valve repair and atrial septal defect closure, one also with plication of the right ventricle. The latter had a spontaneously subsiding junctional ectopic tachycardia rhythm disturbance in the immediate postoperative period. The other patient underwent a series of operations resulting in a Fontan procedure.

\section{Discussion}

This retrospective study of all consecutive live-born EA patients referred to one of the six Dutch pediatric heart centers over a 25-year period shows that 16 out of 93 pediatric EA patients exhibited rhythm disturbances during childhood or adolescence. Two died in the neonatal period: one because of a suspected arrhythmic event and one due to incessant SVT. The 14 patients still alive all showed (intermittently) preexcitation and all but one had arrhythmic events, most commonly paroxysmal SVT. In nine patients, arrhythmic events urged catheter ablation of accessory pathways that were successful in eight patients.

The prevalence of $17 \%$ of arrhythmic events in our EA population of children and adolescents is significantly lower than the prevalence reported in adult EA patients [2]. Adult EA patients have a higher prevalence of arrhythmic events because they not only show preexcitation but also can show prolonged PR interval, ectopic atrial tachycardia, atrial flutter, and atrial fibrillation. These arrhythmic events are caused by tricuspid regurgitation-induced right atrial enlargement, or due to secondary alterations of the right atrial myocardium from previous cardiac surgery, or occur postoperatively as a result of incisional atrial tachycardia. Surprisingly, all surviving pediatric EA patients with arrhythmic events also had (intermittently) preexcitation, rendering a preexcitation prevalence of $15 \%$ in this pediatric population of EA patients. This prevalence is not different from the ones reported in populations of EA patients of all ages, ranging from $10 \%$ to $21 \%$ [2, 3, 6, 7, 9, $11,13,14,17,18,24,25,27]$. As EA is a malformation of the right side of the heart, it is not surprising that in our study, as in others $[2,3,6,7,9,11,13,14,17,18,24,25$, 27], only right-sided accessory pathways are found. The pediatric algorithm to predict the location of the accessory pathway based on QRS polarity in all ECG leads as devised by Boersma et al. [4] appeared to be more congruent with the results during catheter ablation than the adult algorithm as developed by d'Avila [8].

Little is known about the prevalence of preexcitation in neonates with EA. Starnes et al. [24] and Knott-Craig et al. [18] reported no preexcitation in their patients, yet the number of neonates studied was very limited (five and three, respectively). Celermajer et al. [7] found a prevalence of $10 \%$ ( 5 out of 50 neonates). This is in accordance with the current study with a prevalence of $10 \%$ in neonates $(6 / 58)$.

The estimated prevalence of the WPW pattern in the general population is reported to be $0.01-0.3 \%$. However, this might be an underestimation because an intermittent type of WPW pattern is common [23]. The prevalence of WPW increases in a population with congenital heart defects, in particular EA [16].

Five of the EA patients with preexcitation were detected during follow-up because of arrhythmia-related symptoms. Most probably, preexcitation was not detected at the time of EA diagnosis because of the intermittent nature of the WPW pattern, as already demonstrated by Munger et al. [19] and Goudevenos et al. [12]. The clinical presentation and natural history of patients with accessory pathways is highly variable. Cardiac arrhythmias, most frequently paroxysmal supraventricular tachycardia, occur in approximately $50 \%$ of individuals who have ventricular preexcitation $[1,12,19]$. Furthermore, only half of the patients with accessory pathways have their first tachycardia at $<20$ years of age [22].

Treatment of patients with WPW pattern depends on the existence of arrhythmias and their frequency and severity. Patients with symptomatic arrhythmia might be managed in the long term with antiarrhythmic drugs or with catheter ablation of the accessory pathway. Al-Khatib et al. [1] concluded that if the patients' paroxysmal supraventricular tachycardia is satisfactorily controlled by a beta-blocker, no additional evaluation or therapy is required. In our patient population, which includes patients over a long follow-up time span, 6 of the 11 symptomatic patients had undergone catheter ablation, 2 patients planned to undergo catheter ablation in the near future, and 5 patients were controlled satisfactorily with antiarrhythmic drugs. None of the asymptomatic patients in this study received antiarrhythmic treatment nor were they evaluated electrophysiologically. At present, the consensus in The Netherlands is that patients with symptomatic WPW should undergo electrophysiology study and catheter ablation of the accessory pathways. A consensus had not yet been reached concerning the treatment of patients with asymptomatic WPW. Pappone et al. [20] suggested evaluating the risk of arrhythmias by means of electrophysiology study and ablating the high-risk patients. However, the definition of these high-risk patients remains unclear [26].

It has been suggested that in children with EA, catheter ablation has a lower success rate and the risk of recurrence is higher [5].) These observations could not be confirmed in our study.

The authors believe that for EA children with symptomatic WPW, the treatment of choice should be radiofrequency catheter ablation. Whether asymptomatic patients with EA and WPW pattern need to be treated is still controversial. 


\section{Study Limitations}

This is a retrospective study of all 93 patients referred to six pediatric heart centers over a 25 -year period. As such, all limitations of retrospective studies apply.

\section{Conclusions}

In our study of the pediatric EA patients, rhythm disturbances were present in $17 \%$. All but one of these patients with arrhythmias showed (intermittently) preexcitation. This prevalence of rhythm disturbances in childhood and adolescence is significantly lower than reported in adult patients with the same cardiac malformation. Supraventricular arrhythmias are the most common disturbances in the pediatric EA population; these symptomatic patients are well treated with radio-frequency catheter ablation. Life-threatening rhythm disturbances are not frequent early in life.

Open Access This article is distributed under the terms of the Creative Commons Attribution Noncommercial License which permits any noncommercial use, distribution, and reproduction in any medium, provided the original author(s) and source are credited.

\section{References}

1. Al-Khatib SM, Pritchett EL (1999) Clinical features of WolffParkinson-White syndrome. Am Heart J 138:403-413

2. Jost CHA, Connolly HM, Dearani JA, Edwards WD, Danielson GK (2007) Ebstein's anomaly. Circulation 115:277-285

3. Attie F, Rosas M, Rijlaarsdam M, Buendia A, Zabal C, Kuri J, Granados N (2000) The adult patient with Ebstein anomaly Outcome in 72 unoperated patients. Medicine (Baltimore) 79: 27-36

4. Boersma L, Garcia-Moran E, Mont L, Brugada J (2002) Accessory pathway localization by QRS polarity in children with Wolff-Parkinson-White syndrome. J Cardiovasc Electrophysiol 13:1222-1226

5. Cappato R, Schluter M, Weiss C, Antz M, Koschyk DH, Hofmann T, Kuck KH (1996) Radiofrequency current catheter ablation of accessory atrioventricular pathways in Ebstein's anomaly. Circulation 94:376-383

6. Celermajer DS, Bull C, Till JA, Cullen S, Vassillikos VP, Sullivan ID, Allan L, Nihoyannopoulos P, Somerville J, Deanfield JE (1994) Ebstein's anomaly: presentation and outcome from fetus to adult. J Am Coll Cardiol 23:170-176

7. Celermajer DS, Cullen S, Sullivan ID, Spiegelhalter DJ, Wyse RK, Deanfield JE (1992) Outcome in neonates with Ebstein's anomaly. J Am Coll Cardiol 19:1041-1046

8. d'Avila A, Brugada J, Skeberis V, Andries E, Sosa E, Brugada P (1995) A fast and reliable algorithm to localize accessory pathways based on the polarity of the QRS complex on the surface ECG during sinus rhythm. Pacing Clin Electrophysiol 18: 1615-1627

9. Driscoll DJ, Mottram CD, Danielson GK (1988) Spectrum of exercise intolerance in 45 patients with Ebstein's anomaly and observations on exercise tolerance in 11 patients after surgical repair. J Am Coll Cardiol 11:831-836

10. Frescura C, Angelini A, Daliento L, Thiene G (2000) Morphological aspects of Ebstein's anomaly in adults. Thorac Cardiovasc Surg 48:203-208

11. Gentles TL, Calder AL, Clarkson PM, Neutze JM (1992) Predictors of long-term survival with Ebstein's anomaly of the tricuspid valve. Am J Cardiol 69:377-381

12. Goudevenos JA, Katsouras CS, Graekas G, Argiri O, Giogiakas V, Sideris DA (2000) Ventricular pre-excitation in the general population: a study on the mode of presentation and clinical course. Heart 83:29-34

13. Hong YM, Moller JH (1993) Ebstein's anomaly: a long-term study of survival. Am Heart J 125:1419-1424

14. Jaiswal PK, Balakrishnan KG, Saha A, Venkitachalam CG, Tharakan J, Titus T (1994) Clinical profile and natural history of Ebstein's anomaly of tricuspid valve. Int J Cardiol 46:113-119

15. Kapusta L, Eveleigh RM, Poulino SE, Rijlaarsdam ME, du Marchie Sarvaas GJ, Strengers JL, Delhaas T, de Korte CL, Feuth T, Helbing WA (2007) Ebstein's anomaly: factors associated with death in childhood and adolescence: a multi-centre, longterm study. Eur Heart J 28:2661-2666

16. Khositseth A, Danielson GK, Dearani JA, Munger TM, Porter CJ (2004) Supraventricular tachyarrhythmias in Ebstein anomaly: management and outcome. J Thorac Cardiovasc Surg 128:826833

17. Kiziltan HT, Theodoro DA, Warnes CA, O'Leary PW, Anderson BJ, Danielson GK (1998) Late results of bioprosthetic tricuspid valve replacement in Ebstein's anomaly. Ann Thorac Surg 66:1539-1545

18. Knott-Craig CJ, Goldberg SP, Overholt ED, Colvin EV, Kirklin JK (2007) Repair of neonates and young infants with Ebstein's anomaly and related disorders. Ann Thorac Surg 84:587-592 discussion 592-583

19. Munger TM, Packer DL, Hammill SC, Feldman BJ, Bailey KR, Ballard DJ, Holmes DR Jr, Gersh BJ (1993) A population study of the natural history of Wolff-Parkinson-White syndrome in Olmsted County, Minnesota, 1953-1989. Circulation 87:866-873

20. Pappone C, Manguso F, Santinelli R, Vicedomini G, Sala S, Paglino G, Mazzone P, Lang CC, Gulletta S, Augello G, Santinelli O, Santinelli V (2004) Radiofrequency ablation in children with asymptomatic Wolff-Parkinson-White syndrome. N Engl J Med 351:1197-1205

21. Paranon S, Acar P (2008) Ebstein's anomaly of the tricuspid valve: from fetus to adult: congenital heart disease. Heart 94:237-243

22. Rodriguez LM, de Chillou C, Schlapfer J, Metzger J, Baiyan X, van den Dool A, Smeets JL, Wellens HJ (1992) Age at onset and gender of patients with different types of supraventricular tachycardias. Am J Cardiol 70:1213-1215

23. Sarubbi B, D'Alto M, Vergara P, Calvanese R, Mercurio B, Russo MG, Calabro R (2005) Electrophysiological evaluation of asymptomatic ventricular pre-excitation in children and adolescents. Int J Cardiol 98:207-214

24. Starnes VA, Pitlick PT, Bernstein D, Griffin ML, Choy M, Shumway NE (1991) Ebstein's anomaly appearing in the neonate. A new surgical approach. J Thorac Cardiovasc Surg 101:1082-1087

25. Watson H (1974) Natural history of Ebstein's anomaly of tricuspid valve in childhood and adolescence. An international cooperative study of 505 cases. Br Heart J 36:417-427

26. Wellens HJ (2004) Catheter ablation for cardiac arrhythmias. N Engl J Med 351:1172-1174

27. Yetman AT, Freedom RM, McCrindle BW (1998) Outcome in cyanotic neonates with Ebstein's anomaly. Am J Cardiol 81:749754 